\title{
DIMENSIONALITY AND VALIDITY OF THE OPERATIONAL PERFORMANCE CONSTRUCT IN THE AVIATION INDUSTRY: A FACTOR ANALYTIC APPROACH
}

DOI: 10.17261/Pressacademia.2020.1326

RJBM- V.7-ISS.4-2020(9)-p.299-321

\section{Waribugo Sylva}

University of Port Harcourt, Faculty of Management Sciences, P.O.BOX 419 CHOBA, Rivers State, Nigeria Sylva.waribugo@uniport.edu.ng , ORCID: 0000-0002-2976-4771

Date Received: October, 11, 2020

Date Accepted: December 21, 2020

To cite this document

Sylva, W. (2020). Dimensionality and validity of the operational performance construct in the aviation industry: a factor analytic approach.

Research Journal of Business and Management (RJBM), V.7(4), p.299.321.

Permanent link to this document: $\underline{\text { http://doi.org/10.17261/Pressacademia.2020.1326 }}$

Copyright: Published by PressAcademia and limited licensed re-use rights only.

\section{ABSTRACT}

Purpose- Operational performance is critical to competitive advantage, market share and financial performance of organisations. These benefits of operational performance translate to the socioeconomic growth and development of nations. Despite the relevance of this construct, there is paucity of validated scales on it in the airlines' sector. This study, therefore, conceptualized, dimensionalized and validated the operational performance construct in the civil aviation sector.

Methodology- I exhumed 49 items from the vast literature on operational performance in several sectors, including the airline industry. I contacted managers in the aviation sector and experts in the field to confirm face and content validity. I then engaged an initial sample of 213 workers in the 18 Nigerian domestic airlines and subjected the proposed items to Exploratory Factor Analysis (using IBM SPSS version 27). Furthermore, I enlisted another sample of 201 respondents and used the second set of data to conduct a Confirmatory Factor Analysis (using IBM SPSS Amos version 26).

Findings - The initial 49 items passed the test of face and content validity. Exploratory Factor Analysis resulted in the extraction of 29 items from the initial 49 items, representing five principal components (quality, cost, responsiveness, innovation and safety). Upon Confirmatory Factor Analysis, the final 29-item instrument passed the tests of validity and reliability. The proposed overall measurement model had a good fit with the sample data.

Conclusion- Based on the findings, the study emphasized the need for managers in the airline sector to be aware that the twenty nine observable indicators validated in this study can be deployed to improve their organisations' operational performance via quality, cost, responsiveness, innovation and safety. The paper reveals some methodological limitations and suggested that structural models on the nexus between operational performance and other variables, such as organizational culture and environmental turbulence, be developed and tested in diverse settings.

Keywords: Aviation industry, confirmatory factor analysis, exploratory factor analysis, operational performance. JEL Codes: C52, L80, L93, M10

\section{INTRODUCTION}

Operational performance has continued to attract the attention of managers and industry watchers. There is convergence of opinion in scholarly literature that operational performance is the bedrock of quality practices and the overall performance of organisations (Salem, 2003; Sharma \& Modgil, 2020), which is anchored on reduction of cost, waste and order time, efficiency in production, service delivery, cycle time, environmental responsibility and regulatory compliance (Heizer, Render, Munson \& Sachan, 2017).

Moreover, operational performance is a key promoter of competitive advantage (Narasimhan \& Das, 2001; Schroeder, Shah \& Xiaosong-Peng, 2011). Furthermore, Operational performance is important to firms as it reflects improvement in experiential quality in terms of waiting time (Ko, Mai, Shan \& Zhang, 2019) and flexibility of service delivery (Kaynak, 2008), leading to increased revenue and profits for companies (Zhang \& Xia, 2013). 
Specifically, in the aviation sector, operational performance correlates with safety, innovation (Ward, Duray, Leong \& Sum, 1995; McCardle, Rousseau \& Krumwiede, 2019), user satisfaction, passenger loyalty (Peng, 2009; Kumar, Batista, \& Maull, 2011), market share and the financial performance of the airport, airlines and service providers (Tsikriktsis, 2007).

It is a common notion in performance measurement literature that what cannot be measured cannot be improved (Kaplan \& Norton, 1996; Tzanakakis, 2013; Lingard, Wakefield \& Blismas, 2013). Thus, organisations that wish to improve their operational performance need to first of all measure it accurately. According to Melnyk, Stewart and Swink (2004), metrics and performance measurement are essential in converting an organization's vision or mission into reality.

The importance of operational performance to the overall health and effectiveness of organisations has necessitated researchers to come up with various metrics. Despite the prevalence of these metrics, operations managers barely understand them because most of them do not have uniform number or types of measures and are "often poorly articulated" (Melnyk et al, 2004).

Curiously, while the numerous metrics for operational performance have been used especially for supply chains and logistics (e.g. Lyu, Chen \& Huo, 2019), information technology (Cámara, Fuentes \& Marín, 2015) and the pharmaceutical (e.g. Sharma \& Modgil, 2020) and manufacturing sectors (e.g. Baird, Hu \& Reeve, 2011; Chavez, Gimenez, Fynes, Wiengarten \& Yu, 2013; Onofrei, Prester, Fynes, Humphreys \& Wiengarten, 2019), there appears to be none that simultaneously measures how efficiently airlines, in particular, improve quality, reduce cost and ensure on-time service delivery, while being flexible and innovative within a culture that promotes safety and environmental sustainability.

Given the dynamic and unpredictable nature of the aviation industry, laced with bottle neck competition, demands for environmental responsibility and the increasing adoption of innovative techniques and processes, it has become more important than ever to develop a metric on how airlines can assess the extent of improvement in their day-to-day operations. Although most of the previous studies in diverse industry settings have used operational performance as a reflective construct of variables such as cost, quality, delivery and flexibility, I proposed that it is a composite of quality, cost, responsiveness (on-time delivery and service flexibility), innovation and safety/environment.

I therefore conducted a comprehensive study in the Nigerian aviation industry to unambiguously define and facilitate an understanding of the operational performance construct, coupled with the development of a robust instrument that measures the facets of the construct. I ensured that there was congruence between the conceptual definition and actual measurement (Schwab 1980) of the operational performance construct. To achieve this aim, the rest of this paper assumes the following trajectory:

Firstly, I embarked on a comprehensive review of related literature pertaining to the concept of operational performance and its measures. Secondly, I interviewed scholars, organisational experts and managers in the aviation industry on the nature and level of manifestation of operational performance in the sector. Thirdly, after diligent review of the extant literature and inputs from researchers, managers and industry icons, I developed a theorizing model that captured operational performance as a composite of quality, cost, responsiveness (service timeliness and flexibility), innovation and safety/environment.

Following the above, I constructed an instrument (questionnaire) on operational performance, anchored on a 5-point Likert's scale. The proposed measures of operational performance, with their accompanying indicators, were again subjected to rigorous scrutiny of experts to ascertain face and content validity. In addition, I conducted an Exploratory Factor Analysis (EFA), using an initial sample, to explore the underlying factor structure and have a parsimonious conceptual understanding of the operational performance construct. A second sample of respondents was enlisted for Confirmatory Factor Analysis (CFA) of the instrument: to examine the factor structure revealed by the EFA and to confirm it through reliability, validity and model fitness statistics. The use of two independent studies for EFA and CFA was based on the recommendation of Gerbing and Hamilton (1996). I deployed the International Business Machines Corporation's Statistical Package for Social Sciences (IBM SPSS) version 27 and the Analysis of Moment Structures statistical module (IBM SPSS Amos) version 26 to conduct the analyses.

This study marks a watershed in extending the literature on operational performance in the aviation sector. The paper also furnishes a deeper understanding and insight on the critical elements that strike a favourable chord for the enhancement of airlines' operational performance.

The rest of the paper gives details of literature review on the concept of operational performance and its measures. Following this, the paper provides a detailed list of the items generated from the extant rich literature on operational performance, across various industry settings, and tailored to suit the civil aviation sector. Furthermore, the paper substantiated the factorability of the study construct through the factor reduction approach known as Exploratory Factor Analysis, and established the reliability, validity (via Confirmatory Factor Analysis) and goodness of fit of the instrument and the associated model. The final parts of the paper are discussion, implications, limitations and suggestions for future research directions. 


\section{OPERATIONAL PERFORMANCE}

A firm's operational performance (OP) is a measure of its efficiency in utilizing resources, and to innovatively create quality goods and services in a timely, responsive and safe manner without significant harm to the environment. According to Heizer et al. (2008), OP is ability of an organization in reducing costs, order-time, lead-time, thereby improving the overall effectiveness and distribution capacity of the organization. Similarly, Amarjit, Manjeet, Neil and Harvinder (2016) opine that operational performance is an aggregate measure of how efficiently a firm utilizes its resources in its core operations to generate revenues and profits in the long-run. The principle of operational performance lays great emphasis on innovation, quality, timely product/service delivery, maximum conservation of resources, environmental responsibility and regulatory compliance ( $\mathrm{O}^{\prime} \mathrm{Brien}$, 2009; Prajogo, Chowdhury, Yeung \& Cheng, 2012).

Furthermore, operational performance can also be viewed as the extent to which an organisation implements its operations strategy, towards contributing to the superordinate goals. Moreover, Schroeder et al. (2011) submits that operational performance signifies the degree of realization of the competitive priorities set by managers. I define operational performance as the extent to which an organization improves quality, reduces cost and ensures on-time service delivery, while being flexible and innovative within a culture that promotes safety and environmental sustainability.

Organizations stand to harvest several benefits whenever they increase their operational performance. These benefits include higher levels of market share (Tsikriktsis, 2007), user satisfaction, passenger loyalty (Kumar et al, 2011) and competitive advantage (Schroeder et al., 2011). Other outcomes are: improvement in experiential quality in terms of waiting time (Ko et al, 2019), flexibility of service delivery (Kaynak, 2008), safety, innovation and environmental sustainability (McCardle et al, 2019), leading to increased revenue and profits for companies (Zhang \& Xia, 2013).

Due to these numerous benefits mentioned above, firms have deployed various practices to increase operational performance. Such practices include effective supply chain management, green production (Prajogo, Tang \& Lai, 2014), lean manufacturing (Petkova \& Dam, 2014) and Total Quality Management (Vanichchinchai \& Igel, 2011).

\section{MEASURES OF OPERATIONAL PERFORMANCE}

There are no commonly agreed measures of operational performance (Bayraktar, Demirbag, Lenny Koh \& Tatoglu, 2009). Although the most rampant latent indicators of operational performance are cost, quality, delivery and flexibility (Hallgren $\&$ Olhager, 2000; Pagell \& Krause, 2002; Melnyk et al., 2004), there are several other measures advanced by researchers. Various scholars have used various measures of OP based on the industry type, research philosophy and the phenomena being investigated.

For instance, some studies (e.g. Flynn, Huo \& Zhao, 2010; Devaraj, Krajewski, Wei, 2007; Lyu, Chen, Huo, 2018; Sharma, 2020) used operational performance as a single construct with non-uniform multiple indicators. Other studies (e.g. Cámara et al, 2015) dimensionalized operational performance into operational flexibility and delivery performance. Moreover, operational performance has also been bifurcated into quality management and inventory management (Baird, et al, 2011; Saleh, Sweis \& Mahmoud, 2018).

Furthermore, operational performance has been measured as a composite of cost, quality, delivery and flexibility (Cua, McKone \& Schroeder, 2001; Onofrei et al, 2019). Nabass and Abdallah (2018) used the above measures, with each having multiple indictors. Pagell \& Krause (2002) extended the measures of operational performance to unit price of manufacturing, total cost, product quality, delivery speed, delivery dependability, flexibility, and speed of new product introductions.

Similarly, Jabbour, Jabbour, Govindan, Teixeira \& Freitas (2013) deployed cost, quality, flexibility, delivery, new product development, and time-to-market for new products as measures of operational performance, while Nawanir, Teong \& Othman (2013) used quality, inventory minimization, delivery, productivity and cost, with each measure having single item.

In addition, Abdallah, Phan \& Matsui (2016) dimensionalised operational performance as cost, quality, delivery, flexibility and innovativeness - using single indicators for each latent variable. More recently, McCardle et al (2019) demarcated operational performance into exploitative capabilities (comprising cost, quality, and delivery) and explorative capabilities (innovation, and environmental and safety practices).

Following the above, I propose that operational performance is a composite of quality, cost, responsiveness (on-time delivery and service flexibility), innovation and safety. 


\subsection{Quality}

Quality is the degree to which a product conforms to user expectation (Barnes, 2008). Quality can also be viewed as a measure of the amount of desirable attributes in a product. The quality of intangible product is measured in terms of services quality. According to Parasuraman, Zeithaml and Berry (1985), service quality is the perceived difference between customer expectations and service performance. I define quality as a measure of the extent of durability, reliability, functionality, superiority and overall excellence of a product or service which leads to favourable user experience. Higher quality leads to higher user satisfaction, loyalty, market share and revenues.

In the context of the aviation industry, quality is seen as a combination of physical and intangible attributes of the airlines and their staff that offer flights experiences in line with customer's expectation. For Lovelock and Weinburg (1993), all things being equal, quality is the most critical element of that passengers respond to. Thus, the provision of quality services is the greatest preoccupation of managers in the airline industry (Wells \& Wensveen, 2004). The organisational benefits of delivering superior quality include improved brand positioning, passenger retention/ loyalty, market share and profitability - resulting in competitive advantage and organisational success (Whiteley, 1991; Berry \& Parasurman, 1994).

Parasuraman, Zeithaml and Berry (1988) dimensionalized service quality into tangibles, reliability, responsiveness, assurance and empathy. Notwithstanding the popularity of these dimensions, they do not have universal application (Rosen \& Karwan, 1994) and only a few of scholars (e.g. Sultan and Simpson, 2000; Change \& Yeh, 2002) have adopted them in the civil aviation sector. In most of these studies, reliability was found to be the most critical indicator of service quality (Clifford, Cunningham \& Moomkyu, 1994).

The service quality construct gained traction in the airline industry through the works of Gourdin (1998) who decomposed it into price, safety, and timeliness. Before then, Mersha and Adlakha (1992) had advanced readiness to correct errors, task aptitude, courteousness, responsiveness, and tolerance as attributes of service quality. Other indicators of service quality proposed by scholars who studied airlines are: timeliness, food and beverage quality, seat comfort, advocate price, safety, baggage movement, check-in (ground) process and on-board (in-flight) services, aircraft type or brand, overbooking and customer complaints (see Elliot \& Roach, 1993; Ostrowski, O’Brien \& Gordon, 1993; Truitt \& Haynes, 1994; Chen \& Chang, 2005).

Literature concerning the airline industry suggests that quality is reflected in: (1) up-to-date aircraft and in-flight facility, (2) comfortable in-flight seats, (3) convenience of scheduling flights, (4) good meal, (5) interesting in-flight entertainment services, (6) neatness of staff, (7) willingness of employees to help passengers, (8) courtesy and politeness of employees and availability of non-stop flight (Park, Robertson \& Wu, 2006). Quality is also observed by (9) newness of the aircraft, (10) comfort due to functional air conditioners (Saha \& Theingi, 2009), (11) cleanliness and pleasantness of in-flight facilities (Ahn \& Lee, 2011; Chen, Tseng \& Lin, 2011), (12) baggage handling capacity and (13) reliability of scheduled flights (Tiernan, Rhoades, Waguespack Jr, 2008).

\subsection{Cost}

Bowersox, Closs and Cooper (2009) submit that operational cost is the total amount incurred to carry out a specific operation. I define cost as a measure of the naira value of the resources used to produce goods or deliver services; the required payment to manufacture a product or create utility. Cost elements differ based on the industry. Total cost could include holding cost, ordering cost, direct labor cost, inspection costs, administrative and handling costs. One of the principal goals of organisations is to minimize cost in order to maximize profit. Thus, firms deploy cost reduction strategies that emphasize reduction of inventories, elimination of non-value added activities and maximization of resource utilization.

According to Belobaba, Odoni and Barnhart (2015), the major operating cost elements in the airline sector are fuel cost, direct labor cost, depreciation cost, service cost, maintenance cost, and airport charges and handling costs. With regard to ranking, jet fuel and labour costs account for the highest percentage of airlines' operational costs (O'Connor, 2001; Berrittella, La Franca \& Zito, 2009). Fuel cost is influenced by age of aircraft, fuel efficiency of the carrier's fleet, aircraft weight, distance taxied or flown, wind condition and cruise altitude (Doganis, 2010), while labour cost is mainly a function of the salaries of the flight crew, cabin crew and maintenance employees. Maintenance cost include machine equipment purchase costs, quality inspection costs and hangar costs, whereas passenger service cost consists of cost of meals, beverages and cabin crew supplies. Lastly, travel agents' commissions fall under reservations and sales costs (Eller \& Moreira, 2014).

Moreover, as the airlines grapple with intense competition and environmental volatilities, various innovative cost control measures are implemented to ensure their survival and improve their overall performance. One of such response is the emergence of low cost airlines (Atalik \& Özel, 2007), which provide competitive low-cost flights and services for their customers without compromising safety and quality. Specifically, low-cost airlines deploy low-cost strategy by operating high-density seating 
arrangement, single or at most two types of aircrafts, point-to-point network, short-distance flights, no in-flight meals or free beverages (no-frills), low-level of automation, and direct ticketless sales (Seristö \& Vepsäläinen, 1997). These airlines are not interested in using service quality to achieve competitive advantage. Rather, they lower their costs to provide competitive fares for various market segments (Graham \& Vowels, 2006).

Following the above, Chang \& Shao (2011) advocated five policy thrusts to control costs in airlines, namely: fuel cost minimization policy, staff productivity improvement policy, simplification of in-flight operations, reduction of aircraft maintenance cost, and lean operating procedure. Moreover, airlines implement low-cost strategy by (1) reducing dead weight of aircrafts, (2) replacing old aircrafts, (3) ensuring fuel saving, (4) minimizing taxi-out times, (5) adjusting en route flight plans and using alternate airports, (6) allocating reasonable flight hours for cabin crew and discouraging over-time hours, (7) sharing maintenance resources with other airlines, (8) building an effective supply chain network, (9) accelerating direct ticket sales, and (10) encouraging ticketless check-ins and bar code boarding passes (Chang \& Shao, 2011).

\subsection{Responsiveness (on-time delivery and service flexibility)}

The concept of responsiveness suggests that organisations face the twin challenges of on-time delivery and flexibility. A responsive firm is that which provides a service in a timely and flexible manner. I define responsiveness as a firm's ability to deliver products or services to its customers in a timely manner, and swiftly reconfigure or adjust resources to respond to changing customers' preferences and emergencies.

Service organizations endeavour to reduce the time between when a customer makes a demand or places an order and when they receive them (Slack, Chambers \& Johnston, 2007). I define on-time delivery as a form of timeliness that measures the ability of a firm to meet or respond to user demand within a commonly agreed timeframe. In the context of the aviation industry, ontime delivery is the promptness with which airlines respond to customers' demands when they make bookings, the time they spend at the airport on preflight activities and the flight time. Timeliness of operations is important as it reduces turnaround time and the overall stress on the customers, thereby leading to higher levels of passenger satisfaction (Namukasa, 2013). Moreover, Vlachos and Lin (2014) provided empirical evidence that complaints about flight delays and punctuality inhibit passenger loyalty. Some strategies firms adopt to deliver prompt services are: accurate demand forecasting and simulation, efficient coordination of work processes, changing the layout of facilities and optimizing transportation algorithms.

In addition to the need for on-time delivery in a competitive and dynamic environment, organisations are faced with the challenge of flexibility. According to Rosenzweig, Tubiello, Goldberg, Mills and Bloomfield (2002), flexibility is the ability of a firm to seamlessly reconfigure and reallocate resources in a highly competitive environment to meet the constant fluctuations in demand "volume, product mix, and schedules" (p.441). Flexible firms briskly react to changes in time, cost and customer's value with minimum penalty. I define flexibility as a swift adaptation process triggered by rapid fluctuations in demand in terms of product or service specification, volume, price, place and timely delivery. This may involve changing the features of a product or procedures of a service to match the prevailing requirements. Flexibility helps organizations to optimize on operational costs and time, and find new ways to respond rapidly to the ever-changing market and customer needs thus giving the business a competitive edge.

Specifically, the airline sector often faces disturbances such as technical breakdowns, missing passengers, striking workers, airspace congestion or poor weather conditions, which cause delays and further delays, due to interdependencies between various aircraft or crews. Schedule disruptions such as flight cancellation can arise from these disturbances. Moreover, changing customer and regulatory requirements present airlines with the option of reconfiguring their strategies, structures, processes and resources. Thus, how well airlines adjust operations or swap resources to suit the changing business contexts, while maintaining total system functioning, will determine their level of competitiveness and overall performance (Nair, Fernández\& Segura, 2011).

In order to overcome these challenges, airlines deploy flexible strategy by reducing or increasing fleet size, increasing delay tolerance or carrying out low-cost recovery activities (lonescua \& Kliewera, 2011). Flexible scheduling involves swapping of resources such as aircraft or crew, rerouting of passengers, adjusting departure time or cancelling flights, or using reserve or standby resources, until all resources for operation are available.

A granular look at theory reveals that airlines are responsive when: (1) ground handling services are executed promptly and appropriately, (2) in-flight services are delivered promptly, (3) there is no delay in passenger, crew and luggage check-ins, (4) airline has on-time departure and arrival, (5) staff quickly and effectively handle complaints, (6) ticketing is quick, easy and user friendly, (7) Information of flight status is updated promptly using several channels, (8) passengers can choose the seats they prefer, (9) resources are easily swapped, rescheduled or reallocated during severe disruptions or emergencies (see Keating, Rugimbana \& Quazi, 2003; Chen, 2008; Oyewole, Sankaran \& Choudhury, 2008; Tiernan, Rhoades, Waguespack Jr, 2008; Ahn \& Lee, 2011; Chou, Liu, Huang, Yih, \& Han 2011; Ionescua \& Kliewera, 2011; Lau, Kwek \& Tan, 2011;Wyman, 2012). 


\subsection{Innovation}

Innovation is viewed as the successful introduction of new or improved management ideas, processes, methods, patents, practices, technologies, products and services into an organisation. Narvekar and Jain (1996) declare that innovation is the process of generating a fresh idea and using it to create valuable business outcomes. For Hurley and Hult (1998), innovation is the "willingness of the members of an organization to consider the adoption" of new management techniques or initiatives (p. 44). I define innovation as a process that involves the introduction of a new idea, process, technique, managerial practice, product or service; or the modification and improvement of these, geared towards optimizing the performance indices of an organization. The newness of these elements depends on the perception of an individual or firm that introduces the innovation (Damanpour, 1992). Thus, that which is classified as innovation in one firm may not be seen as innovation by another firm.

A distillation of the innovation literature reveals that an organization is said to be innovative if it: (1) frequently introduces new ideas to its services than competitors (2) goes ahead of its competitors in the introduction of new product or service offerings (Heracleous\&Wirtz, 2014), (3) adopts the latest technology ahead of its competitors, (4) constantly improves its business processes, (5) often develops new management approaches, (6) constantly encourages "idea employees" to develop novel solutions to problems and (7) improvises on new methods and processes when conventional methods cannot solve problems (Wang \& Ahmed, 2004).

Business organisations continue to embrace innovation because it is vehicle for knowledge creation, sustainable growth, competitive advantage and survival (Coakes \& Smith, 2007; Al-kalouti, Kumar, Kumar, Garza-Reyes, Upadhyay \& Zwiegelaar, 2020). Moreover, firms that continuously innovate are more equipped to cope with market turbulence and uncertainty (De Medeiros, Ribeiro, \& Cortimiglia, 2014). Also, innovation enables firms to penetrate new markets and increases customer satisfaction (Jaskyte, 2011; Śledzik, 2013), which promotes higher market share and profit levels (Gaynor, Bradner, lansiti, \& Kung, 2001).

Airlines achieve competitive edge and sustainable growth not only through offering quality service or deploying low-cost strategy. Long-term survival, competitive differentiation and growth are dividends of innovation. Thus, airlines deeply realize the need to launch new fleets and services, enter profitable markets, and deploy new business models in order to have a fit with the ever changing business environment and to meet stakeholders' expectations (Dasgupta \& Gupta, 2009).

Following the above, innovative airlines introduce new business models and advanced experiential services that continuously exceed customers' expectations. High investment in point-to-point flights, adoption of management rotation system, use of youngest fleets (Heracleous \& Wirtz, 2014), purchase of large volumes of particular aircraft to obtain huge discount, and new reward management methods are some of the business model innovations in the industry. Moreover, innovation in advanced experiential services include the use of the latest on-board entertainment systems, allowing business and first class passengers to order dishes of their choice and eat before embarking on flight, provision of flat-bed seats, having the roomiest business class seats and provision of in-flight massaging services and suites for business meetings, coupled with limousine or bike pickup.

Furthermore, airlines also embark on technological innovations by purchasing next generation aircrafts in order to reduce fuel costs. They also use innovative applications such as self-check-in kiosks or mobile phone barcode solutions to enhance process stability and service quality. More to that, innovative airlines deploy state-of-the-art IT solutions such as wireless networks, integrated computer reservation systems, databases and host systems to coordinate activities along the value chain.

\subsection{Safety}

Safety is a condition whereby individuals, communities and natural environment are protected from danger, hazard or risk. Atkins (1991) view safety as: (1) "the quality of not being dangerous" (p. 169), (2) "the condition of not being in danger" (p. 169) and the condition of "a place where you are safe from a particular danger" (p. 171). Thus, a person or place is safe when there is a very low possibility of harm or damage, measured against specified thresholds and standards. It is a state of inoculation from hazards attributable to natural forces or random human errors. The above notion on safety relates only to the absence or presence of acceptable level of danger, but does not address safety as a perceptual phenomenon. To this end, Maurice, Lavoie, Laflamme, Svanström, Romer and Anderson (2001) define safety as "a state in which hazards and conditions leading to physical, psychological or material harm are controlled in order to preserve the health and well-being of individuals and the community" (p.238). I define safety as a non-significant probability of occurrence of physical injury, physiological impairment, psychological harm, material damage, or environmental hazard in a workplace or community. Thus, Safety could also be viewed as freedom from any event that negatively affects the health and well-being of individuals and the community, or causes significant reduction of the quality of the environment. Safety as a process involves all activities carried out by organizations to ensure that physical injury, 
physiological impairment, psychological harm, material damage, or environmental hazard in a workplace or community are avoided, or do not exceed acceptable levels.

Airline safety is a fundamental component of operational performance, and improvement in safety record contributes to passenger loyalty, stakeholder satisfaction the overall success of airlines (Chen \& Chen, 2012; Hussain, Al Nasser \& Hussain, 2015). Safety in airlines addresses two major areas, namely: (1) freedom from unacceptable injury, damage, accidents or crash, and (2) protection of the environment (Hudson, 1997). Thus, airline operators are not only concerned with the safety of their employees and passengers, but also how their operations affect the safety of the environment and the immediate host community. Safety issues of concern range from accidents, injuries and plane crashes to emission of noise, industrial wastes and greenhouse gases (McManners, 2016).

In order to ensure safety, airline managers carry out the following activities: (1) stop unsafe operations, (2) comprehensively investigate accidents to identify both immediate and remote causes for the prevention of future occurrences, (3) provide sufficient safety training and retraining for employees, (4) strictly observe accident preventive measures, (5) promptly rectify any fault, (6) frequently embark on safety audit (Zohar, 1980; Edkins \& Coakes, 2007), (7) adopt environmentally friendly technologies, (8) purchase aircrafts that are fuel efficient and have low total carbon emissions, (9) dispose old aircrafts that have high noise levels, (10) encourage tree planting to mitigate the impact of our operations on the environment, and (11) uses waste treatment plant to protect the environment from toxic waste (Alemayehu \& Brocke, 2010).

\section{SCALE DEVELOPMENT AND EXPLORATORY FACTOR ANALYSIS}

I followed the recommendations of Hurley, Scandura, Schriesheim, Brannick, Seers, Vandenberg and Williams (1997), and Anderson and Gerbing (1988) on the development of scales. I embarked on an exhaustive literature search to exhume the associated measures of operational performance. I generated 49 items that reflect the proposed facets of operational performance. These items were conceptually factored into the five facets of operational performance, namely: quality, cost, responsiveness, innovation and safety.

I approached 10 managers in the aviation sector as well as five psychometricians, in the area of performance analytics, who modified some of the items in order to keep them simple, appropriate and meaningful (Kimberlin \& Winterstein, 2008). Both managers and experts agreed that the 49 items adequately and sufficiently reflect the operational performance construct and its proposed dimensions.

Table 1 shows the proposed dimensions, their operational definitions and the generated items with corresponding sources.

Table 1: The Operational Performance Construct and its Proposed Dimensions and Items

Construct: Operational performance

Definition: The extent to which an organization improves quality, reduces cost and ensures on-time service delivery, while being flexible and innovative within a culture that promotes safety and environmental sustainability.

\begin{tabular}{|c|c|c|c|}
\hline Dimension & $\begin{array}{l}\text { Operational } \\
\text { Definition }\end{array}$ & Items Generated & Sources \\
\hline Quality & $\begin{array}{l}\text { A measure of the } \\
\text { extent of durability, } \\
\text { reliability, } \\
\text { functionality, } \\
\text { superiority and } \\
\text { overall excellence } \\
\text { of a product or } \\
\text { service which leads } \\
\text { to favourable user } \\
\text { experience. }\end{array}$ & 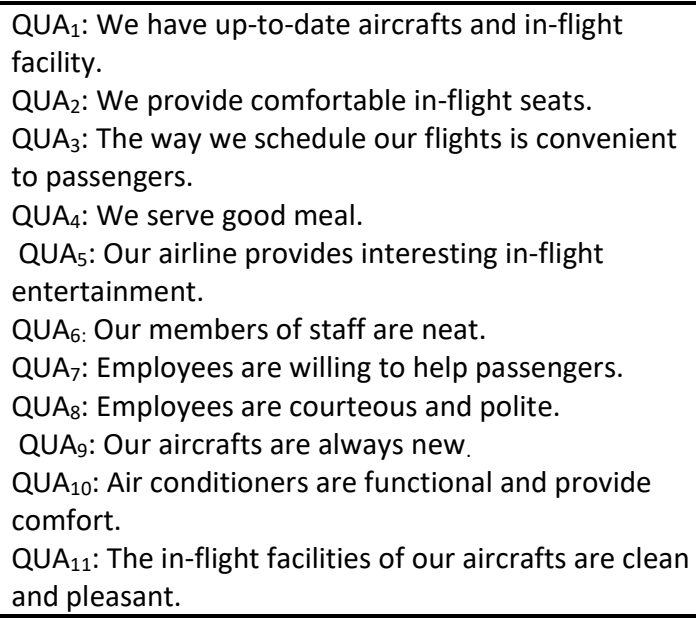 & $\begin{array}{l}\text { Park, Robertson and } \\
\text { Wu (2006) } \\
\text { Tiernan, Rhoades, and } \\
\text { Waguespack Jr (2008). } \\
\text { Saha and Theingi } \\
\text { (2009) } \\
\text { Ahn and Lee (2011) } \\
\text { Chen, Tseng and Lin } \\
\text { (2011) }\end{array}$ \\
\hline
\end{tabular}




\begin{tabular}{|c|c|c|c|}
\hline & & $\begin{array}{l}\text { QUA }_{12}: \text { We handle baggage without getting missing, } \\
\text { damaged or delayed. }\end{array}$ & \\
\hline Cost & $\begin{array}{l}\text { The naira value of } \\
\text { the resources used } \\
\text { to produce goods } \\
\text { or deliver services; } \\
\text { the required } \\
\text { payment to } \\
\text { manufacture a } \\
\text { product or create } \\
\text { utility. }\end{array}$ & $\begin{array}{l}\operatorname{COS}_{1} \text { : Dead weight of our aircrafts is substantially } \\
\text { reduced. } \\
\operatorname{COS}_{2} \text { : We always replace old aircrafts. } \\
\operatorname{COS}_{3} \text { : We observe fuel saving measures. } \\
\operatorname{COS}_{4} \text { : We minimizing taxi-out times. } \\
\operatorname{COS}_{5} \text { : We adjust en route flight plans and using } \\
\text { alternate airports } \\
\operatorname{COS}_{6} \text { : We allocate reasonable flight hours for cabin } \\
\operatorname{crew} \text { and discourage over-time hours. } \\
\operatorname{COS}_{7}: \text { Maintenance resources are shared with other } \\
\text { airlines. } \\
\operatorname{COS}_{8}: \text { We have an effective supply chain network. } \\
\operatorname{COS}_{9}: \text { Our airline sells tickets directly to passengers. } \\
\operatorname{COS}_{10}: \text { We encourage ticketless check-ins and bar code } \\
\text { boarding passes. }\end{array}$ & $\begin{array}{l}\text { Chang and Shao } \\
\text { (2011). }\end{array}$ \\
\hline Responsiveness & $\begin{array}{l}\text { A firm's ability to } \\
\text { deliver products or } \\
\text { services to its } \\
\text { customers in a } \\
\text { timely manner, and } \\
\text { swiftly reconfigure } \\
\text { or adjust resources } \\
\text { to respond to } \\
\text { changing } \\
\text { customers' } \\
\text { preferences and } \\
\text { emergencies. }\end{array}$ & $\begin{array}{l}\mathrm{RES}_{1} \text { : Our ground handling services are executed } \\
\text { promptly and appropriately. } \\
\mathrm{RES}_{2} \text { : Our in-flight services are delivered promptly. } \\
\mathrm{RES}_{3} \text { : There is no delay in passenger, crew and luggage } \\
\text { check-ins } \\
\mathrm{RES}_{4} \text { : Our arrivals and departures are always on-time. } \\
\mathrm{RES}_{5} \text { : Our staff members quickly and effectively handle } \\
\text { Complaints. } \\
\mathrm{RES}_{6} \text { : Ticketing is quick, easy and user friendly. } \\
\mathrm{RES}_{7} \text { : Information on flight status is updated promptly } \\
\text { using several channels. } \\
\mathrm{RES}_{8} \text { : Passengers can choose the seats they prefer. } \\
\mathrm{RES}_{9} \text { : Resources are easily swapped, rescheduled or } \\
\text { reallocated during severe disruptions or emergencies. }\end{array}$ & $\begin{array}{l}\text { Keating, Rugimbana } \\
\text { and Quazi (2003) } \\
\text { Chen (2008) } \\
\text { Oyewole, Sankaran } \\
\text { and Choudhury (2008) } \\
\text { Tiernan, Rhoades and } \\
\text { Waguespack Jr (2008) } \\
\text { Ahn and Lee (2011) } \\
\text { Chou et al. (2011) } \\
\text { lonescua and Kliewera } \\
\text { (2011) } \\
\text { Lau, Kwek and Tan } \\
\text { (2011) } \\
\text { Wyman (2012) }\end{array}$ \\
\hline Innovation & $\begin{array}{l}\text { A process that } \\
\text { involves the } \\
\text { introduction of a } \\
\text { new idea, process, } \\
\text { technique, } \\
\text { managerial } \\
\text { practice, product or } \\
\text { service; or the } \\
\text { modification and } \\
\text { improvement of } \\
\text { these, geared } \\
\text { towards optimizing } \\
\text { the performance } \\
\text { indices of an } \\
\text { organization. }\end{array}$ & 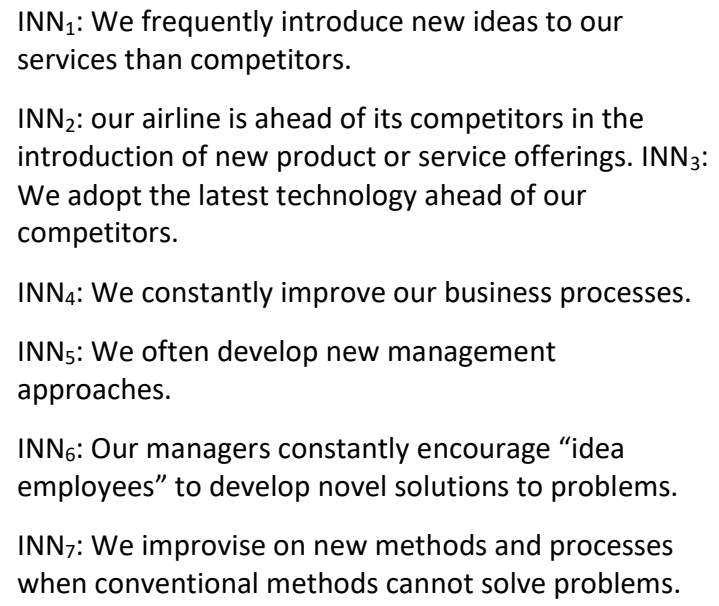 & $\begin{array}{l}\text { Wang and Ahmed } \\
\text { (2004). Heracleous } \\
\text { and Wirtz (2014). }\end{array}$ \\
\hline
\end{tabular}




\begin{tabular}{|c|c|c|c|}
\hline Safety & $\begin{array}{l}\text { A non-significant } \\
\text { probability of } \\
\text { occurrence of } \\
\text { physical injury, } \\
\text { physiological } \\
\text { impairment, } \\
\text { psychological harm, } \\
\text { material damage, } \\
\text { or environmental } \\
\text { hazard in a } \\
\text { workplace or } \\
\text { community. }\end{array}$ & 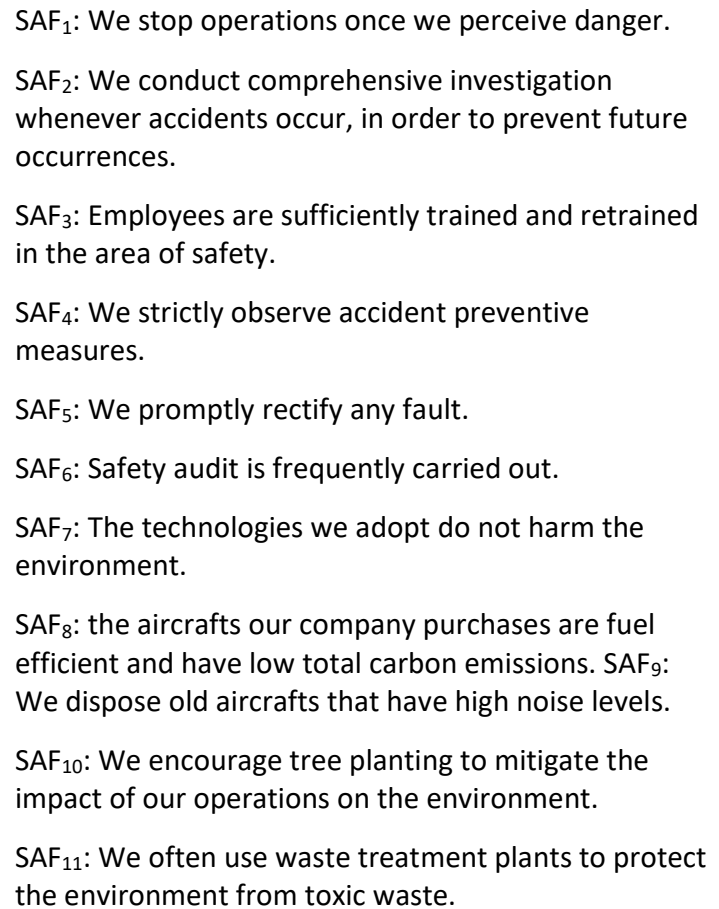 & $\begin{array}{l}\text { Zohar (1980) } \\
\text { Edkins and Coakes } \\
\text { (2007) } \\
\text { Alemayehu and Brocke } \\
(2010)\end{array}$ \\
\hline
\end{tabular}

\subsection{Exploratory Factor Analysis (Study 1)}

The proposed items were anchored on a 5-point Likert's scale and administered as an instrument to employees (including managers, supervisors, pilots, flight attendants, and check-in staff) in the civil aviation sector, covering Port Harcourt, Owerri, Calabar, Lagos, Abuja and kano. I deployed the key informant approach (Kumar, Stern \& Anderson, 1993) to have a snowball sample of 308 employees from 18 domestic airlines. This sample size is presumed acceptable since it exceeds the required size of at least 200 observations to conduct a reasonable EFA, so far as the inter-item correlations are strong (MacCallum, Widaman, Zhang, \& Hong, 1999).

In order to increase response rate, I utilized various sources, such as personal emails, survey monkey to administer the questionnaire. Moreover, I made several telephone calls and used gifts as well as little monetary offer to catalyze the response rate (Singer \& Groves\& Corning, 1999; Yu, Alper, Nguyen, Brackbill, Turner, Walker, Maslow \&Zweig, 2017).

After 10 weeks, I retrieved 221 responses. Out of the 221 copies of the questionnaire retrieved, with a response rate of $71.8 \%, 8$ copies were discarded due to missing responses. A case-wise deletion method (Malhotra, 1999) was used in analyzing missing responses in which only cases with complete records were included in order to maintain consistency. Thus, a total of 213 cases were finally used for the analysis. Table 2 shows the demographic characteristics of the final sample.

Table 2: Demographic Characteristics of the Sample $(N=213)$

\begin{tabular}{|l|c|c|}
\hline Variable & Description & Percent \\
\hline \multirow{3}{*}{ Gender } & Male & $68.3 \%$ \\
\cline { 2 - 3 } & Female & $31.7 \%$ \\
\hline \multirow{3}{*}{ Age (Years) } & Age bracket & Percent \\
\cline { 2 - 3 } & $<26$ & $6.6 \%$ \\
\cline { 2 - 3 } & $26-35$ & $26.4 \%$ \\
\cline { 2 - 3 } & $36-45$ & $45.3 \%$ \\
\cline { 2 - 3 } & $>45$ & $21.7 \%$ \\
\hline
\end{tabular}




\begin{tabular}{|c|c|c|}
\hline Job Tenure (Years) & Tenure Bracket & Percent \\
\cline { 2 - 3 } & $<5$ & $31.6 \%$ \\
\cline { 2 - 3 } & $5-10$ & $37.9 \%$ \\
\cline { 2 - 3 } & $11-15$ & $19.4 \%$ \\
\cline { 2 - 3 } & $16-20$ & $6.3 \%$ \\
\cline { 2 - 3 } & $>20$ & $4.8 \%$ \\
\hline
\end{tabular}

Table 2 reveals that that out of the total of final sample of 213 respondents, $68.3 \%$ were males, whereas $31.7 \%$ were females. Hence, the number of males is more than twice that of females in the airline sector in Nigeria. Moreover, $45.3 \%$ fall within the age bracket of $36-45$ years, whereas $26.4 \%$ are between $26-35$ years, $21.7 \%$ are above 45 , and $6.6 \%$ are below 26 years in age. Hence, more than three-fifths of the employees are within the age bracket of 26-45 years, with about three-fifths progressing towards retirement age. The mean age is 37.9 years $(S D=2.83)$. Table 2 also reveals that $37.9 \%$ of the respondents have worked in the sector between $5-10$ years, followed by $31.6 \%$ who have worked less than 5 years. Also, $19.4 \%$ have worked between $11-$ 15 years, $6.3 \%$ for $16-20$ years and $4.8 \%$ have been working in the sector for more than 20 years. Hence, more than one-thirds of employees have worked between 5-10 years followed by a little less than one-thirds who have worked less than 5 years. Moreover, the mean total duration of work experience was 9.01 years $(S D=4.11)$. The preponderance of employees who have worked for not more than 10 years is traceable to the recent massive employment in the sector.

Next is the result on Principal Component Analysis (PCA). Several scholars (e.g. Fabrigar, Wegener, Maccallum \& Strahan, 1999; Osborne \&Costello, 2009) agree that the PCA as an appropriate method in implementing the EFA because "results produced by factor analysis and PCA are quite similar and is often negligible in terms of interpretation" (Maskey, Feih \& Nguyen, 2018, p. 92). Specifically, the PCA was used because the analysis involves finding the smallest number of factors that will account for the correlations among the measured variables - that is, how and to what extent items were correlated to a battery of underlying unobserved variables (Byrne, 1998; Yong \& Pearce, 2013).

Thus, Exploratory Factor Analysis was conducted on 49 items of Operational Performance using the PCA with varimax rotation to ascertain unidimensionality. During the EFA, several indicators were deleted because they either had poor factor loadings less than the recommended 0.50 threshold under their respective latent variables or cross-loaded more than 0.4 on multiple factors

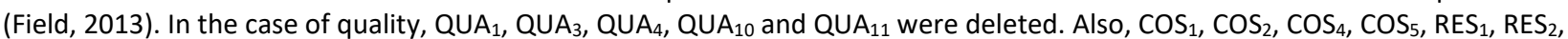
$\mathrm{RES}_{3}, \mathrm{RES}_{6}, \mathrm{INN}_{6}, \mathrm{INN}_{7}, \mathrm{SAF}_{1}, \mathrm{SAF}_{2}, \mathrm{SAF}_{5}, \mathrm{SAF}_{6}$ and $\mathrm{SAF}_{7}$ were suppressed because they loaded below 0.5 , and as such are practically irrelevant or redundant (Hair, Black, Babin \& Anderson, 2013).

Furthermore, by way of data inspection (Howard, 2016), outputs regarding KMO (Kaiser-Mayer-Olkin) Measure of Sampling Adequacy, Bartlet's Test of Sphericity, Eigen values and Cronbach's alpha were observed, together with the variances explained by the respective factors.

The Kaiser-Meyer-Olkin (KMO) measure of sampling adequacy is an index (ranging from 0-1) that "indicates whether the correlations between variables can be explained by the other variables in the dataset" (Sarstedt \& Mooi, 2014, p. 242). KMO thresholds below 0.50 are unacceptable, whereas values between $0.50-0.59,0.60-0.69,0.70-0.79,0.80-0.89$ and 0.90 and above are miserable, mediocre, middling, meritorious and marvelous, respectively (Kaiser, 1974; Malhotra \& Dash, 2007).

The Bartlett's test of sphericity was used to test the null hypothesis that all non-diagonal elements in a correlation matrix are zero in the population. A statistically significant $(p<0.5)$ Bartlett's test of sphericity at $95 \%$ confidence level indicates that sufficient correlations exist among the variables to proceed with factor analysis (Hair.Jr., Black, Babin, Anderson \&Tatham, 2006).

Another index used in EFA is the Kaiser criterion (Kaiser, 1960, 1970) of eigenvalues. According to Osborne \& Banjanovic (2016), an eigenvalue is "a representation of the aggregated item-level variance associated with a factor" (p.13). The eigenvalue for a given component measures the variance in all the variables which are included in that component, where the default cut off eigenvalue is mainly set at 1.0. Hence, if a factor has a low eigenvalue $(<1.0)$, then it is contributing little to the explanation of variances in the variables and may be ignored as redundant with more important factors (Fabrigar\& Wegener, 2012).

The most popular estimate of internal consistency of observables in an instrument is the Cronbach's alpha (Cronbach, 1951; Cronbach \& Shavelson, 2004). It is a measure of the extent to which survey items correlate with each other. Statistically, $\alpha$ is an estimate of "the proportion of variance that is systematic or consistent in a set of survey responses" (Vaske, Beaman \& Sponarski, 2016, p. 3). An alpha between $0.65-0.80$ is often considered substantial for an instrument used in social or management research (Spector, 1992; Vaske,2008). The results of the EFA for the OP dimensions are presented in Table 3. 
Table 3: Results of EFA for OP Factors $(N=213)$

\begin{tabular}{|c|c|c|c|c|c|}
\hline \multirow[b]{2}{*}{ Latent Variables and their Indicators } & \multicolumn{4}{|c|}{ Factors } & \multirow[b]{2}{*}{5} \\
\hline & 1 & 2 & 3 & 4 & \\
\hline \multicolumn{6}{|l|}{ Quality } \\
\hline QUA_9: Our aircrafts are always new & 0.823 & & & & \\
\hline QUA_2: We provide comfortable in-flight seats. & 0.811 & & & & \\
\hline QUA_12: We handle baggage without getting missing, damaged or delayed & 0.803 & & & & \\
\hline QUA_7: Employees are willing to help passengers. & 0.792 & & & & \\
\hline QUA_5: Our airline provides interesting in-flight entertainment. & 0.777 & & & & \\
\hline QUA_8: Employees are courteous and polite. & 0.764 & & & & \\
\hline QUA_6: Our members of staff are neat. & 0.761 & & & & \\
\hline \multicolumn{6}{|l|}{ Cost } \\
\hline COS_3: We observe fuel saving measures. & & 0.841 & & & \\
\hline COS_7: Maintenance resources are shared with other airlines. & & 0.833 & & & \\
\hline COS_8: We have an effective supply chain network. & & 0.830 & & & \\
\hline COS_g: Our airline sells tickets directly to passengers. & & 0.800 & & & \\
\hline COS_10: We encourage ticketless check-ins and bar code boarding passes. & & 0.779 & & & \\
\hline $\begin{array}{l}\text { COS_6: We allocate responsible flight hours for cabin crew and discourage } \\
\text { over-time hours }\end{array}$ & & 0.768 & & & \\
\hline \multicolumn{6}{|l|}{ Responsiveness } \\
\hline RES_4: Our arrivals and departures are always on-time. & & & 0.862 & & \\
\hline $\begin{array}{l}\text { RES_9: Resources are easily swapped, rescheduled or reallocated during } \\
\text { severe disruptions or emergencies. }\end{array}$ & & & 0.832 & & \\
\hline $\begin{array}{l}\text { RES_7: Information on flight status is updated promptly using several } \\
\text { channels. }\end{array}$ & & & 0.820 & & \\
\hline RES_5: Our staff members quickly and effectively handle complaints. & & & 0.798 & & \\
\hline RES_8: Passengers can choose the seats they prefer. & & & 0.774 & & \\
\hline \multicolumn{6}{|l|}{ Innovation } \\
\hline $\begin{array}{l}\text { INN_2: Our airline is ahead of its competitors in the introduction of new } \\
\text { product or service offerings. }\end{array}$ & & & & 0.828 & \\
\hline INN_3: We adopt the latest technology ahead of our competitors. & & & & 0.823 & \\
\hline INN_1: We frequently introduce new ideas to our services than competitors. & & & & 0.782 & \\
\hline INN_4: We constantly improve our business processes. & & & & 0.763 & \\
\hline INN_5: We often develop new management approaches. & & & & 0.761 & \\
\hline \multicolumn{6}{|l|}{ Safety } \\
\hline SAF_4: We strictly observe accident preventive measures. & & & & & 0.871 \\
\hline $\mathrm{SAF}_{3}$ : Employees are sufficiently trained and retrained in the area of safety. & & & & & 0.868 \\
\hline SAF_9: We dispose old aircrafts that have high noise levels. & & & & & 0.862 \\
\hline
\end{tabular}


SAF_10: We encourage tree planting to mitigate the impact of our operations

on the environment.

SAF_11: We often use waste treatment plants to protect the environment

from toxic waste.

$\mathrm{SAF}_{8}$ : the aircrafts our company purchases are fuel efficient and have low

total carbon emissions.

NOTE: KMO (Kaiser-Mayer-Olkin) Measure of Sampling Adequacy: Quality $=0.881$, Cost $=0.794$, Responsiveness $=0.827$, Innovation $=0.660$, Safety $=0.757$, Total $\mathrm{KMO}=0.837$; Eigenvalues: Quality $=6.774$, Cost $=5.838$, Responsiveness $=5.101$, Innovation $=5.706$, Safety $=14.901$, Total Eigenvalue $=6.227 ;$ Explained Variance (\%): Quality $=37.731$, Cost $=13.846$, Responsiveness $=12.131$, Innovation $=10.444$, Safety $=14.752$, Total Explained Variance $(\%)=88.904$; Cronbach's Alpha: Quality $=0.786$, Cost $=0.822$, Responsiveness $=0.739$, Innovation $=0.771$, Safety $=0.838$, Total Alpha $=0.775 ;$ Bartlet's Test of Sphericity: Approx. Chi-Square $=945.137, \mathrm{df}=267$, Sig. 0.000 .

Source: IBM SPSS Output

Table 3 reveals that the KMO values for the factors range from mediocre ( 0.660 for Innovation) to meritorious ( 0.881 for quality), with meritorious total KMO of 0.837. Moreover, Bartlett's test values are adequate (Chi-Square $=945.137, \mathrm{df}=267, \mathrm{Sig} .0 .000<$ 0.001 ) at $95 \%$ confidence level, meaning that the correlations between the variables are significantly different from zero. Moreover, the quality factor had largest share of explained variance (37.731) with an eigenvalue of 6.774, whereas innovation factor had smallest share of explained variance (10.444) with an eigenvalue of 5.706. Overall, all factors had eigenvalues higher than one and explained88.904\%total variance of the final 29 items. These outputs indicate that factor analysis has statistical appropriateness and utility for these statement items. Also, the alpha values are acceptable as they range from 0.739 to 0.838 , with a total alpha of 0.775 . Thus, all the blocks are considered homogenous and the items are consistently reasonable in explaining the variances within the model. Next is the descriptive statistics of the operational performance items with the corresponding $r$ and $\quad R^{2}$ values of the measures, as shown in table 4.

Table 4: Descriptive Statistics and Item Total Correlations $(N=\mathbf{2 1 3})$

\begin{tabular}{|c|c|c|c|c|c|c|}
\hline Construct & Indicators & Mean & SD & Item-Total Correlations & $\mathbf{R}$ & $R^{2}$ \\
\hline \multicolumn{7}{|c|}{ Operational Performance } \\
\hline \multirow[t]{7}{*}{ Quality } & QUA_9 & 4.003 & 0.521 & 0.341 & 0.471 & \\
\hline & QUA_2 & 3.828 & 0.663 & 0.432 & 0.403 & \\
\hline & QUA_12 & 3.115 & 0.550 & 0.411 & 0.322 & \\
\hline & QUA_7 & 4.672 & 0.703 & 0.392 & 0.496 & 0.398 \\
\hline & QUA_5 & 3.332 & 0.514 & 0.407 & 0.374 & \\
\hline & QUA_8 & 3.963 & 0.508 & 0.333 & 0.411 & \\
\hline & QUA_6 & 4.471 & 0.671 & 0.327 & 0.472 & \\
\hline \multirow[t]{6}{*}{ Cost } & $\cos \_3$ & 4.032 & 0.555 & 0.421 & 0.338 & \\
\hline & $\operatorname{COS}_{-7}$ & 3.827 & 0.649 & 0.397 & 0.484 & \\
\hline & $\mathrm{COS}_{-8}$ & 3.168 & 0.563 & 0.400 & 0.379 & 0.345 \\
\hline & $\cos \_9$ & 3.902 & 0.715 & 0.431 & 0.414 & \\
\hline & COS_10 & 4.111 & 0.694 & 0.399 & 0.385 & \\
\hline & $\cos \_6$ & 3.621 & 0.590 & 0.384 & 0.300 & \\
\hline \multirow[t]{5}{*}{ Responsiveness } & RES_4 & 3.352 & 0.730 & 0.429 & 0.363 & \\
\hline & RES_9 & 3.020 & 0.582 & 0.337 & 0.491 & \\
\hline & $\mathrm{RES}_{-7}$ & 3.622 & 0.518 & 0.345 & 0.328 & 0.328 \\
\hline & RES_5 & 4.149 & 0.606 & 0.402 & 0.367 & \\
\hline & RES_8 & 3.720 & 0.595 & 0.388 & 0.396 & \\
\hline \multirow[t]{5}{*}{ Innovation } & INN_2 & 4.119 & 0.648 & 0.348 & 0.301 & \\
\hline & INN_3 & 3.013 & 0.555 & 0.442 & 0.412 & \\
\hline & INN_1 & 4.588 & 0.617 & 0.333 & 0.402 & 0.312 \\
\hline & INN_4 & 3.906 & 0.546 & 0.386 & 0.337 & \\
\hline & INN_5 & 3.825 & 0.713 & 0.448 & 0.388 & \\
\hline \multirow[t]{3}{*}{ Safety } & $\mathrm{SAF}_{-} 4$ & 3.094 & 0.561 & 0.305 & 0.402 & \\
\hline & $S A F \_3$ & 4.444 & 0.693 & 0.404 & 0.351 & \\
\hline & SAF_9 & 3.668 & 0.597 & 0.413 & 0.465 & 0.330 \\
\hline
\end{tabular}




\begin{tabular}{|lllll|}
\hline SAF_10 & 3.811 & 0.706 & 0.386 & 0.399 \\
SAF_11 & 4.503 & 0.574 & 0.408 & 0.374 \\
SAF_8 & 3.773 & 0.622 & 0.396 & 0.386 \\
\hline
\end{tabular}

Source: IBM SPSS v 27 Output

Table 4 reported the mean, standard deviation and correlations of the items, with the coefficient of determination of the principal components. The output shows that all the statement items manifest highly in the sector $[(M=3.013, S D=0.555)$ to $(M=4.672$, $S D=0.703)$ ]. Moreover, the item total correlations among the observables and their corresponding underlying factors are satisfactory (>0.3), thus providing additional proof for internal consistency (Polit \& Beck, 2009). Also, the $r$ values of the items (ranging from 0.300 to 0.496 ) and the R-Squared values of the principal components (ranging from 0.312 to 0.398 ) signify that the final items have predictive acceptance and the model fits the exploratory data (Henseler, Ringle \& Sinkovics, 2009).

\subsection{Confirmatory Factor Analysis (Study 2)}

Study 2 involves the collection of data from a second sample of 201 employees in Nigerian airlines. This sample is reasonable based on the 1:10 rule of sample size for CFA, espoused by Hair et al (2013). By calculation, a minimum of 20 items $\times 10=200$ data points are needed for the study. Hence, 201 data points would be considered adequate sample size to run the CFA and draw inferences.

The measurement model for operational performance has 5 latent variables, namely: Quality, Cost, Responsiveness, Innovation and Safety, with observable variables of 7,6,5,5 and 6, respectively - these making a total of 29 measurable indicators.

A granular check on the retrieved copies of the 201 copies of the questionnaire reveals that there were no missing data. We then conducted normality checks on the data using IBM SPSS version 27, to ensure that the data meet the basic assumptions of conducting CFA. We found that skewness and kurtosis of the individual variables were below 2.00 and 7.00 , respectively (Chou \& Bentler, 1995). Moreover, there was no fundamental problem of outliers.

I then exported the data to IBM SPSS Amos version 26 to examine the factor loadings and compute validity and reliability statistics.

\subsection{Convergent Validity and Reliability}

A factor loading above 0.70 suggests that an indicator exhibits a satisfactory level of reliability. Moreover, an indicator is reliable when its squared loading scores at least $50 \%$ variance (Hulland, 1999). Also, for a latent variable to be adequately explained by its indicators, the average of the squared loadings of its indicators (Average Variance Extracted) should be at least $50 \%$ (Hair, Black \& Babin, 2010). The theoretical name for Average Variance Extracted (AVE) is Convergent Validity, also called communality or Dillon- Goldstein coefficient (Tenenhaus, Esposito Vinzi, Chatelin, \& Lauro, 2005). It is an estimate that determines the average quantity of variances in indicators that explain the underlying factor (Fornell \& Larcker, 1981; Taylor \& Hunter, 2003). Thus, a latent variable is said to be free from problem of convergent validity when its Average Variance Extracted (AVE) is not less than 0.5 .

Furthermore, reliability of the latent variables is assessed via composite reliability and Cronbach's alpha scores. Composite reliability is a measure of homogeneity, which signifies the proportion of the total composite variance that serves as an estimation of the true-score variance of each latent variable (Wang \& Stanley, 1970). The Cronbach's alpha (denoted by $\alpha$ ) is the popular measure of an instrument's internal consistency or reliability (Cronbach,1951). It is an estimate of "the proportion of variance that is systematic or consistent in a set of survey responses" (Vaske, Beaman \& Sponarski, 2016, p. 3). As a rule, a set of latent variables is said to be consistent in explaining the variances that constitute them if composite reliability and alpha values are not less than 0.7 (Nunnally \& Bernstein, 1994).

Table 5 shows the factor loadings with Average Variance Extracted and the reliability estimates of the latent variables. 
Table 5: Average Variance Extracted and the Reliability Estimates of LVs

\begin{tabular}{|c|c|c|c|c|c|c|}
\hline \multirow[t]{3}{*}{ Constructs } & \multirow[t]{3}{*}{ Indicators } & \multicolumn{3}{|c|}{ Convergent Validity } & \multicolumn{2}{|c|}{ Internal Consistency Reliability } \\
\hline & & Loadings & $\begin{array}{l}\text { Indicator } \\
\text { Reliability }\end{array}$ & AVE & $\begin{array}{l}\text { Composite } \\
\text { Reliability }\end{array}$ & $\begin{array}{l}\text { Cronbach's } \\
\text { Alpha }\end{array}$ \\
\hline & & $>0.70$ & $>0.50$ & $>0.50$ & $>0.70$ & $0.70-0.90$ \\
\hline \multirow{7}{*}{ QUALITY } & QUA_9 & 0.712 & 0.507 & \multirow{7}{*}{0.573} & \multirow{7}{*}{0.877} & \multirow{7}{*}{0.876} \\
\hline & QUA_2 & 0.709 & 0.503 & & & \\
\hline & QUA_12 & 0.836 & 0.699 & & & \\
\hline & QUA_7 & 0.776 & 0.602 & & & \\
\hline & QUA_5 & 0.825 & 0.681 & & & \\
\hline & QUA_8 & 0.715 & 0.511 & & & \\
\hline & QUA_6 & 0.711 & 0.506 & & & \\
\hline \multirow{6}{*}{ COST } & $\cos \_3$ & 0.864 & 0.747 & \multirow{6}{*}{0.607} & \multirow{6}{*}{0.779} & \multirow{6}{*}{0.777} \\
\hline & COS_7 & 0.717 & 0.514 & & & \\
\hline & $\cos \_8$ & 0.790 & 0.624 & & & \\
\hline & COS_9 & 0.812 & 0.659 & & & \\
\hline & COS_10 & 0.722 & 0.521 & & & \\
\hline & COS_6 & 0.759 & 0.576 & & & \\
\hline \multirow{5}{*}{ RESPONSIVENESS } & RES_4 & 0.709 & 0.503 & \multirow{5}{*}{0.621} & \multirow{5}{*}{0.878} & \multirow{5}{*}{0.876} \\
\hline & RES_9 & 0.824 & 0.679 & & & \\
\hline & RES_7 & 0.883 & 0.779 & & & \\
\hline & RES_5 & 0.718 & 0.516 & & & \\
\hline & RES_8 & 0.791 & 0.626 & & & \\
\hline \multirow{5}{*}{ INNOVATION } & INN_2 & 0.898 & 0.806 & \multirow{5}{*}{0.644} & \multirow{5}{*}{0.793} & \multirow{5}{*}{0.790} \\
\hline & INN_3 & 0.793 & 0.629 & & & \\
\hline & INN_1 & 0.708 & 0.501 & & & \\
\hline & INN_4 & 0.824 & 0.679 & & & \\
\hline & INN_5 & 0.777 & 0.604 & & & \\
\hline \multirow{6}{*}{ SAFETY } & SAF_4 & 0.742 & 0.551 & \multirow{6}{*}{0.616} & \multirow{6}{*}{0.840} & \multirow{6}{*}{0.837} \\
\hline & SAF_3 & 0.769 & 0.591 & & & \\
\hline & SAF_9 & 0.837 & 0.701 & & & \\
\hline & SAF_10 & 0.888 & 0.789 & & & \\
\hline & SAF_11 & 0.709 & 0.503 & & & \\
\hline & SAF_8 & 0.747 & 0.558 & & & \\
\hline
\end{tabular}

Source: IBM SPSS Amos v26 output, 2020

Table 5 indicates that all factors loaded above the recommended threshold of 0.7, with the lowest being 0.708 (INN_1) and the highest being 0.898 (INN_2). Also, squared loadings were above 50\%, with the lowest being $50.1 \%$ (INN_1) and the highest being $80.6 \%$ (INN_2). For these reasons, the model has achieved item reliability.

Moreover, AVEs outputs of the dimensions surpassed the recommended threshold of 50\%, with the lowest being $57.3 \%$ (Quality) and the highest being $64.4 \%$ (Innovation). Thus, the variables have achieved convergent validity.

Furthermore, the output indicates that values of composite reliability exceeded the recommended threshold of 0.7 , with the lowest being 0.779 (Cost) and the highest being 0.878 (Responsiveness). Also, reliability figures are above the Nunnalian cut-off value of 0.7 , with the lowest being 0.777 (Cost) and the highest being 0.876 (Responsiveness). Consequently, the results verify that the extracted variables are consistent in explaining the variances that constitute them. 


\subsection{Discriminant Validity}

Analysis on discriminant (divergent) validity reveals the degree to which a cluster of indicators differs from other clusters, even if all the clusters are related to a parent construct. Put in another way, a block of indicators is said to discriminate itself from other blocks within the model if it shares more variance with its own block of indicators than with another latent variable representing a different block of indicators. Statistically, a latent variable does not have discriminant validity problem if the square root of its AVE exceeds its correlation with all other latent variables (Fornell \& Larcker, 1981; Chin, 1998). In addition, both Maximum Shared Variance (MSV) and Average Shared Variance (ASV) of a latent variable should be less than its AVE for discriminant validity to be achieved.

Table 6 shows the output for mean, standard deviation and discriminant validity of the latent variables.

Table 6: Descriptive Statistics of Latent Variables and Test of Discriminant Validity

\begin{tabular}{|c|c|c|c|c|c|c|c|c|c|c|}
\hline $\begin{array}{l}\text { Latent } \\
\text { Variables }\end{array}$ & Mean & SD & AVE & MSV & ASV & QUA & COS & RES & INN & SAF \\
\hline QUA & 3.919 & 0.582 & 0.573 & 0.275 & 0.294 & $\mathbf{0 . 7 5 7}$ & & & & \\
\hline COS & 3.767 & 0.711 & 0.607 & 0.352 & 0.361 & 0.301 & $\mathbf{0 . 7 7 9}$ & & & \\
\hline RES & 3.581 & 0.639 & 0.621 & 0.322 & 0.333 & 0.398 & 0.312 & $\mathbf{0 . 7 8 8}$ & & \\
\hline INN & 3.901 & 0.557 & 0.644 & 0.371 & 0.369 & 0.410 & 0.446 & 0.364 & $\mathbf{0 . 8 0 3}$ & \\
\hline SAF & 3.883 & 0.596 & 0.616 & 0.298 & 0.301 & 0.383 & 0.402 & 0.388 & 0.390 & $\mathbf{0 . 7 8 5}$ \\
\hline
\end{tabular}

Note: SD = Standard Deviation, AVE = Average Variance Extracted, MSV: maximum shared variance; ASV: average shared variance, $\mathrm{QUA}=$ Quality, $\mathrm{COS}=$ Cost, RES = Responsiveness, INN = Innovation, SAF = Safety. The off-diagonal values are the correlations between latent variables, while the diagonal values (in bold)denote the square roots of AVEs.

Source: IBM SPSS Amos v26 output, 2020.

Table 6 indicates that all the dimensions are well correlated, with the lowest correlation existing between Cost and Quality ( $r=$ 0.301), while Innovation - Cost has the highest correlation $(r=0.446)$. This confirms that the latent variables measure a single construct. Furthermore, all the diagonal figures (square roots of the Average Variances Extracted) are higher than 0.7; and are far greater than the off-diagonal figures (correlations between the constructs). This means that although the latent variables tend to measure a single construct they are sufficiently distinct from one another. Moreover, all values of MSV and ASV are lower than their corresponding AVEs. Therefore, the proposed dimensions of Operational Performance have no discriminant validity problem.

Following Oxford and Burry-stock's (1995) scale, the model also suggests that all the proposed dimensions manifest highly in the aviation, with the lowest preponderance recorded for responsiveness $(M=3.581, S D=0.639)$ while quality has the highest manifestation $(M=3.919, S D=0.582)$ in the sector.

\subsection{Model Fit Evaluation}

Hair et al. (2013) recommended that model fit evaluation should report the following: (i) the Chi-Square Minimum Discrepancy (CMIN or $\chi^{2}$ ), degrees of freedom (df) and p-value (ii) an absolute fit index - e.g., Root Mean Square Error of Approximation (RMSEA) or Standardized Root Mean Square Residual (SRMR) (iii) goodness of fit (GOF) index (e.g., CFI or TLI). Based on this recommendation, we examined CMIN/df, CFI, TLI, RMSEA and SRMR coupled with a report on p-value.

The table 7 shows the goodness of fit statistics for the overall measurement model.

Table 7: Summary of Overall Model Fit

\begin{tabular}{|c|c|c|c|c|c|}
\hline $\begin{array}{l}\text { Fit } \\
\text { Indices }\end{array}$ & $\chi^{2} /(d f)$ & CFI & TLI & RMSEA & SRMR \\
\hline Scores & $226.746(96)$ & 0.982 & 0.945 & 0.063 & 0.699 \\
\hline
\end{tabular}

$p=0.0003$

Source: IBM SPSS Amos v 26 output 
Table 7 shows that the overall model has a $\chi^{2}=226.746, d f=96, \chi^{2} /(d f)=2.362$ with $p<0.001$. Additionally, CFI=0.982, TLI=0.945, RMSEA $=0.063$ and SRMR $=0.699$. This confirms that model exhibits acceptable goodness-of-fit to the sample data. Hence, the proposed components with their accompanying indicators can be practically used as subjective measures of the operational performance construct in the aviation sector. Figure 1 is the output of the measurement model via the IBM SPSS Amos $\vee 26$ software.

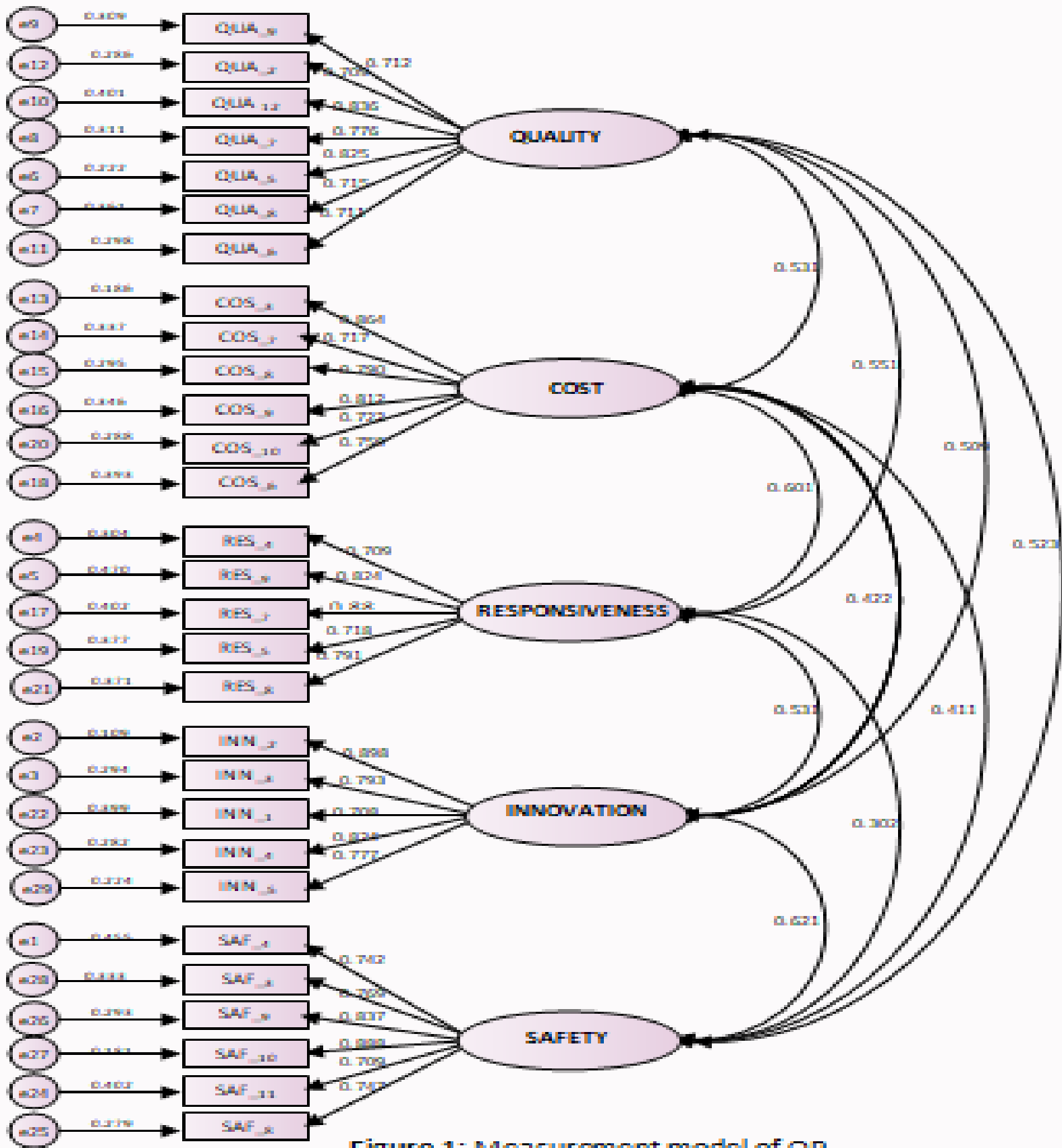

Figure 1: Measurement model of op 


\section{DISCUSSION AND IMPLICATION OF THE STUDY}

The operational performance construct developed and validated in this paper is a milestone contribution to the performance measurement literature of the civil aviation sector.

In this study, after exploratory factor analytic treatment, the retained items were subjected to confirmatory factor analysis whereby they converged in clusters on five sub-constructs. Although the latent variables reflect a larger construct by virtue of the appreciable correlations among them, such correlation values were lower than 0.7. Furthermore, the AVEs of each block of indicators far exceeded the correlation between it and other blocks. This satisfied condition for discriminant validity.

Following the above, it means that employees of the airlines perceived enough difference between Quality, Cost, Responsiveness, Innovation and Safety to qualify them as distinct sub-constructs. Moreover, the Operational Performance model had a good fit with the sample data, based on the overall evaluation of five model fit indices. Therefore, scholars are at liberty to utilize any or a combination of the five dimensions independently.

A major contribution of this study to the literature on operational performance is the inclusion of safety as one of the dimensions. Although quantity, cost, responsiveness and innovation have been documented as dimensions of operational performance (e.g. Jabbour et al., 2013; Nawanir et al., 2013; Abdallah et al., 2016), past studies have largely downplayed the relevance of safety, especially as it concerns the protection of the environment in the day-to-day operations of airlines. It appears only McCardle et al (2019) included "environmental and safety practices" as dimensions of operational performance in "manufacturing supply chains" (p. 8). Thus, the specified measurement model validated in this study appears to be more holistic in capturing the facets of airlines' operational performance, using perceptual metrics (Ketokivi \& Schroeder, 2004) in this age of growing agitation for a safe planet.

Furthermore, this study extends the literature on performance management by providing further illumination to the operational performance construct, while offering more nuanced definitions of the concepts that underpin the phenomenon of interest.

That being said, this study holds practical implication for managers and policy makers who are desirous of addressing performance issues in their organisations. Managers should be aware that the twenty-nine observable indicators validated in this study can be deployed to improve their organisations' operational performance via quality, cost, responsiveness, innovation and safety (see table 3).

\section{LIMITATIONS AND DIRECTIONS FOR FUTURE STUDIES}

The basic limitations of the study emanate from its aim and the methodology. These limitations provide a gateway for future research.

Firstly, the initial list of items that were generated may not be exhaustive. For instance, some authors (e.g. Baird et al, 2011) included inventory management items as part of operational performance, but this study did not include them because I felt they are mainly meant for the manufacturing sector (e.g. Saleh et al, 2018). Although, the validated items are relatively robust, future studies should generate inventory management items that reflect the cost dimension of operational performance, and modify them to suit the aviation sector.

Secondly, none of the validated statement items was coded in reverse form. Future research should consider negatively wording some of the statement items to mitigate response set bias (Chyung, Barkin \& Shamsy, 2018). In addition, future studies should conduct analysis to ascertain the presence or otherwise of common method variance (Podsakoff, MacKenzie, Lee \& Podsakoff, 2003).

Thirdly, Gerbing and Anderson (1988) submit that scales which have been developed and validated should be further retested and replicated using robust methodological approaches. This airlines' operational performance scale appears to be the first, hence future research should add more indicators and retest it in diverse cultures and countries for factorability and validity.

Finally, because the aim of this study is to validate the proposed measurement of operational performance, no structural analysis was conducted on the construct and possible correlates. Thus, researchers can deploy the developed and validated scale in other hypothesized models. For instance, future studies may investigate the nexus between operational performance and other constructs such as corporate culture, in the presence of environmental turbulence. 


\section{REFERENCES}

Abdallah, A. B.,Phan, C. A., \& Matsui, Y. (2016).Investigating the effects of managerial and technological innovations on operational performance and customer satisfaction of manufacturing companies. International Journal of Business Innovation and Research, 10(2/3), $153-183$.

Ahn, T., \& Lee, T. J.(2011). Service quality in the airline industry: Comparison between traditional and low-cost airlines. Tourism Analysis, 16(5), 535-542.

Alemayehu, W., \&Brocke, J. (2010). Sustainability performance measurement-The case of Ethiopian airlines. In: Lecture Notes in Business Information Processing LNBIP, 66, 489-500.

Al-kalouti, J., Kumar, V., Kumar, N., Garza-Reyes, J.,Upadhyay, A., \&Zwiegelaar, J.(2020).Investigating innovation capability and organizational performance in service firms.Briefings in Entrepreneurial Finance, 29(1), 103-113.

Amarjit, G., Manjeet, S., Neil, M., \&Harvinder, S. M. (2016). The impact of operational efficiency on the future performance of Indian manufacturing firms.International Journal of Economics and Finance, 6(10), 259-269.

Anderson, J. C., \&Gerbing, D. W. (1988). Structural equation modeling in practice: A review and recommended two-step approach. Psychological Bulletin, 103(3), 411-423.

Atalik, Ö.,\&Özel, E. (2007). Passenger expectations and factors affecting their choice of low cost carriers-Pegasus Airlines.Paper presented at the Northeast Business and economics association conference, Central ConnecticutState University, New Britain, November 7-9. Pegasus Airlines," paper presented at the Northeast Business.

Atkins, B.T. (1991). Building a lexicon: The contribution of lexicography.International Journal of Lexicography, 4(3), 167-204.

Baird, K., Hu, K. J., \& Reeve, R. (2011). The relationships between organizational culture, total quality management practices and operational performance.International Journal of Operations \& Production Management, 31(7), 789-814.

Barnes, D. (2008). Operations management.1st Edition. Thompson.

Bayraktar, E., Demirbag, M., Lenny Koh, S. C., \& Tatoglu, E. (2009). A causal analysis of the impact of information systems and supply chain management practices on operational performance: Evidence from manufacturing SMEs in Turkey. International Journal of Production Economics, 122(1), 133-149.

Belobaba, P., Odoni, A., \&Barnhart, C. (2015). The global airline industry.John Wiley \& Sons.

Berrittella, M., La Franca, L., \&Zito, P. (2009). An analytic hierarchy process for ranking operating costs of low cost and full service airlines. Journal of Air Transportation Management, 15(5), 249-255.

Berry, L., \& Parasurman, A. (1994). Improving service quality in America: Lessons learned. Academy of Management Executive, 8(2), 32-52.

Bowersox, D.J., Closs, D.J., \& Cooper, M.B. (2009). Supply chain logistics management. $3^{\text {rd }}$ edition. McGraw-Hill.

Byrne, B. M. (1998). Structural equation modeling with LISREL, PRELIS, and SIMPLIS: Basic concepts, applications, and programming. Erlbaum.

Cámara, S. B., Fuentes, J. M., \&Marín, J. M. M. (2015). Cloud computing, Web 2.0, and operational performance. The International Journal of Logistics Management, 26, 426-458.

Chang, Y. H., \& Yeh, C. H. (2002).A survey analysis of service quality for domestic airlines.European Journal of Operational Research, 139(1), 16677.

Chang, Y-H., \& Shao, P-C. (2011). Operating cost control strategies for airlines.African Journal of Business Management, 5(26), 0396-10409.

Chavez, R., Gimenez, C., Fynes, B., Wiengarten, F., \& Yu, Y. (2013). Internal lean practices and operational performance: The contingency perspective of industry clock-speed. International Journal of Operations \& Production Management, 33(5), 562-588.

Chen, C. F., \& Chen, F.C. (2012). Scale development of safety management system evaluation for the airline industry. Analysis and Prevention, $47,177-181$

Chen, F.Y., \& Chang, Y.H. (2005). Examining airline service quality from a process perspective. Journal of Air Transport Management, 11 (2), 79-87.

Chen, Y.H., Tseng, M.L., \& Lin, R-J.(2011). Evaluating the customer perceptions on in-flight service quality. African Journal of Business Management, 5(7), 2854-2864.

Chin, W. W. (1998). The partial least squares approach for structural equation modelling. In G. A. Marcoulides (Ed). Modern methods for business research.295-336. Lawrence Erlbaum Associates.

Chou, C.C., Liu, L.J., Huang, S.F., Yih, J.M., \& Han, T.C. (2011). An evaluation of airine service quality using the fuzzy weighted SERVQUAL method.Applied Soft Computing, 11, 2117-2128. 
Chou, C.P., \& Bentler, P. M. (1995). Estimation and tests in structural equation modeling.In R. H. Hoyle (Ed.), Structural equation modeling: Concepts, issues, and applications.37-55. Sage.

Clifford, Y., Cunningham, L., \&Moomkyu, L. (1994). Assessing service quality as an effective management tool: The case of the airline industry.Journal of Marketing Theory and Practice,Spring, 76-96.

Coakes, E., \& Smith, P.(2007).Developing communities of innovation by identifying innovation champions.The Learning Organization, 14(1), 7485.

Cronbach, L. J. (1951). Coefficient alpha and the internal structure of tests.Psychometrika, 16(3), 297-334.

Cronbach, L. J., \& Shavelson, R. J. (2004). My current thoughts on coefficient alpha and successor procedures.Educational and Psychological Measurement, 64(3), 391-418.

Cua, K., McKone, K., \& Schroeder, R. (2001). Relationships between Implementation of TQM, JIT, and TPM and manufacturing performance.Journal of Operations Management, 19(6), 675-694.

Damanpour, F. (1992). Organizational size and innovation.Organization Studies, 13, 375-402.

Dasgupta, M., \& Gupta, R. (2009). Innovation in organizations.A review of the role of organizational learning and knowledge management.Global Business Review, 10(2), 203-224.

De Medeiros, J. F., Ribeiro, J. L. D., \&Cortimiglia, M. N. (2014). Success factors for environmentally sustainable product innovation: A systematic literature review. Journal of Cleaner Production, 65, 76-86.

Devaraj, S., Krajewski, L., \& Wei, J. C. (2007). Impact of ebusiness technologies on operational performance: the role of production information integration in the supply chain. Journal of Operation Management, 25(6), 1199-1216.

Doganis, R. (1991). Flying off course.2nd edition. Routledge.

Edkins, G., \&Coakes, S. (2007). Measuring safety culture in the Australian regional airline industry: the development of the airline safety culture index (asci). Safety Science, ElsevierScience Publishers, Amsterdam. Retrieved from www.leadingedgesafety.com.au/FolioFiles/175/756Safety\%20Culture.pdf

Eller, R., \& Moreira, M. (2014). The main cost-related factors in airlines management.Journal of Transport Literature, 8(1), 8-23.

Elliott, K. M., \& Roach, D. W. (1993). Service quality in the airlineindustry: Are carriers getting an unbiased evaluation fromcustomers? Journal of Professional Services Marketing, 9(2),71-82.

Fabrigar, L. R., Wegener, D. T., Maccallum, R. C. \&Strahan, E. J. (1999). Evaluating the use of exploratory factor analysis in psychological research. Psychological Methods, 4(3), 272-299

Fabrigar, L. R., \& Wegener, D. T. (2012). Exploratory factor analysis. Oxford University Press.

Flynn, B., Huo, B., \& Zhao, F. (2010). The impact of supply chain integration on performance: A contingency and configuration approach. Journal of Operations Management, 28(1), 58-71.

Fornell, C., \&Larcker, D. F. (1981). Evaluating structural equation models with unobservable variables and measurement error. Journal of Marketing Research. 48, 39-50.

Gaynor, M., Bradner, S., lansiti, M., \& Kung, H. T. 2001.The real options approach to standards for building network-based services. In: 2nd IEEE Conference on Standardization and Innovation in Information Technology; October 3-6, 217-228. Boulder, CO.

Gerbing, D. W., \& Hamilton, J. G. (1996). Viability of exploratory factor analysis as a precursor to confirmatory factor analysis. Structural Equation Modeling a Multidisciplinary Journal, 3(1), 62-72.

Gourdian, K. (1988). Bringing quality back to commercial air travel: The first step forward. Transportation Journal, 27(3), 23-29.

Graham, B., \& Vowels, T. M. (2006). Carriers within carriers:A strategic response to low-cost airline competition. Transport Reviews, 26(1), 105126.

Hair, J.F., Black, W.C., Babin, B.J., \& Anderson, R.E. (2010). Multivariate data analysis.Seventh Edition.Prentice Hall.

Hair, J. F., Black, W. C.,Babin, B. J., Anderson, R.E. (2013).Multivariate data analysis. Pearson New International Edition.Pearson Education Limited.

Hair, J. F., Ringle, C. M., \&Sarstedt, M. (2013). Partial least squares structural equation modeling: Rigorous applications, better results and higher acceptance. Long Range Planning, 46(1-2), 1-12.

Hair.Jr., J. F., Black, W. C., Babin, B. J., Anderson, R. E., \&Tatham, R. L. (2006). Multivariant data analysis.Pearson International Edition. 
Hallgren, M., \&Olhager, J. (2000). Lean and agile manufacturing: External and internal drivers and performance outcomes. Journal of Operations \& Production Management, 29(10), 976-999.

Heizer, J.H., Render, B., \&Weiss, H. J. (2008). Principles of operations management. Pearson Prentice Hall.

Heizer, J., Render, B., Munson, C., \&Sachan, A. (2017). Operations management: Sustainability and supply chain management. $12^{\text {th }}$ edition. Pearson Education.

Henseler, J., Ringle, C. M., \&Sinkovics, R. R. (2009). The useofpartialleastsquares pathmodelingininternational marketing. Advances in International Marketing, 20, 277-319.

Heracleous, L., \&Wirtz, J. (2014). Singapore airlines: Achieving sustainable advantage through mastering paradox.Journal of Applied Behavioral Science, 50(2), 150-170.

Howard. J. W. (2016). Moral subversion and structural entrapment.Journal of Political Philosophy, 24(1), 24-46.

Hudson, P. (1997). Establishing a safety culture in transport industries. Unpublished Paper.

Hulland, J. (1999). Use of partial least squares (PLS) in strategic management research: A review of four recent studies. Strategic Management Journal,20(2), 195-204.

Hurley, A. E., Scandura, T. A., Schriesheim, C. A., Brannick, M. T., Seers, R., Vandenberg, R. J., Williams, L. J. (1997). Exploratory and confirmatory factor analysis: Guidelines, issues, and alternatives. Journal of Organizational Behaviour, 18(6), 667-683.

Hurley, R.F., \&Hult, T.M. (1998) Innovation, market orientation and organizational learning: an integration and empirical investigation.Journal of Marketing, 62, 4, 42-54.

Hussain, R., Al Nasser, A.,\&Hussain, Y.(2015).Service quality and customer satisfaction of a UAE-based airline: Anempirical investigation. Journal of Air Transport Management, 42, 167-175.

Ionescua, L., \&Kliewera, N. (2011). Increasing flexibility of airline crew schedules. Social and Behavioral Sciences, 20,1019-1028.

Jabbour, C.J.C, Jabbour, A.B.L.S., Govindan, K., Teixeira, A.A., \& Freitas, W.R.S (2013).Environmental management and operational performance in automotive companies in Brazil: The role of human resource management and lean manufacturing. Journal of Cleaner Production, $47,129-140$.

Jaskyte, K. (2011). Predictors of administrative and technological innovations in non-profit organizations.Public Administration Review, 71(1), 7786.

Kaiser,H. F. (1960). The application of electronic computers to factor analysis.Educational and Psychological Measurement, $20,141-151$.

Kaiser, H. F. (1970). A second-generation Little Jiffy. Psychometrika, 35, 401-415.

Kaiser, H. F. (1974). An index of factorialsimplicity.Psychometrika, 39, 31-36.

Kaplan, R. S., \& Norton, D. P. (1996). Using the balanced scorecard as a strategic management system.Harvard Business Review,(Jan-Feb), 75-85.

Kaynak, J. L. H. (2008). A replication and extension of quality management into the supply chain.Journal of Operations Management, 26(4), 468489.

Keating, B., Rugimbana, R., \&Quazi, A. (2003). Differentiating between service quality and relationship quality in cyberspace.Journal of Service Theory and Practice,13(3), 217-232.

Ketokivi, M.A. and Schroeder, R.G. (2004). Perceptual measures of performance: fact or fiction? Journal of Operations Management, 22(3), 24764.

Kimberlin, C. L., \&Winterstein, A.G. (2008). Validity and reliability of measurement instruments used in research. American Journal of Health System Pharmacists, 65, 2276-2284.

Ko, D-G., Mai, F., Shan, Z., \& Zhang, D. (2019). Operational efficiency and patient-centered health care: A viewfrom online physician reviews. Journal of Operations Management, 1-27.

Kumar, N., Stern, L. W., \& Anderson, J. C. (1993). Conducting interorganizational research using key informants. The Academy of Management Journal, 36, 1633-1651.

Kumar, V., Batista, L., \&Maull, R. (2011). The impact of operations performance on customer loyalty.Service Science, 3(2), $158-171$.

Lau, T-C,Kwek, C-L., \& Tan, H-P.(2011). Airline e-ticketing service: How e-service quality and customer satisfaction impacted purchase intention. International Business Management, 5(4), 200-208.

Lingard, H., Wakefield, R., \&Blismas, N. (2013). If you cannot measure it, you cannot improve it: Measuring health and safety performance in the construction industry. Conference: 19th Triennial CIB World Building Congress at: Brisbane. 
Lovelock, C. H., \& Weinberg, C. B. (1993). Marketing challenges: Cases \& exercises. (3rd ed.).McGrawHill.

Lyu, G., Chen, L., \&Huo, B. (2019). Logistics resources, capabilities and operational performance: A contingency and configuration approach. Industrial Management Data Systems, 119(2), 230-250.doi.org/10.1108/IMDS-01-2018-0024

MacCallum, R., Widaman, K., Zhang, S., \& Hong, S. (1999). Sample Size in Factor Analysis. Psychological Methods, 4(1), 84-99.

Malhotra, N. K. (1999). Marketing research: An applied orientation.3rd (Ed). Prentice Hall.

Malhotra, N.K., \& Dash, S. (2007). Market research-An applied orientation.Fifth Edition.610-635. Pearson Education.

Maskey, R., Fei, J., \& Nguyen, H. (2018). Use of exploratory factor analysis in maritime research.The asian journal of shipping and logistics, 34, 91111.

Maurice, P., Lavoie, M., Laflamme, L., Svanström, L., Romer, C., \& Anderson, R. (2001). Safety and safety promotion: Definitions for operational developments. Injury Control and Safety Promotion, 8(4), 237-240.

McCardle, J. G., Rousseau, M. B., \&Krumwiede, D. (2019). The effects of strategic alignment and competitive prioritieson operational performance: The role of cultural context. Operations Management Research, 12,4-18.

McManners, P. J. (2016). Developing policy integrating sustainability: A case study into aviation.Environmental Science \& Policy, 57,86-92.

Melnyk, S. A., Stewart, D., \&Swink, M. (2004). Metrics and performancemeasurement in operations management: Dealing withthe metrics maze. Journal of Operations Management, 22(3), 209-218.

Mersha, T., \&Adlakha, V. (1992). Attributes of service quality: The consumers' perspective.International Journal of Service Industry Management, $3(3), 34-45$.

Nabass, E., \&Abdallah, A. (2018). Agile manufacturing and business performance.Business Process Management Journal, doi:10.1108/bpmj-072017-0202.

Nair, S., Fernández, M. \& Segura, J. J. (2011). Flexibility in airline business models with core competence as an indicator.

Namukasa, J. (2013). The influence of airline service quality on passenger satisfaction and loyalty: The case of Uganda airline industry. TQM Journal, 25(5), 520-532.

Narasimhan, R., \& Das, A. (2001). The impact of purchasing integration and practices on manufacturing performance.Journal of Operations Management, 19(5), 593-609.

Narvekar, R., \& Jain, K. (1996). A new framework to understand the technological innovation process.Journal of Intellectual Capital, 7(2),174-186.

Nawanir, G., Teong, K. L., \& Othman, N. S. (2013). Impact of lean practices on operations performance and business performance: Some evidence from Indonesian manufacturing companies.Journal of Manufacturing Technology Management, 24(7), 1019-1050.

Nunnally, J. C., \& Bernstein, J. H. (1994). Psychometric theory. (3rd Ed.).McGraw-Hill.

O'Connor, W. E. (2001). An introduction to airline economics.6th edition. Praeger.

Onofrei, G., Prester, J., Fynes, B., Humphreys, P., \&Wiengarten, F. (2019). The relationship between investments in lean practices and operational performance: Exploring the moderating effects of operational intellectual capital. International Journal of Operations \& Production Management, 39(3), 406-428.

Osborne, J. W., \&Banjanovic, E. S. (2016). Exploratory factor analysis with SAS.SAS Institute.

Osborne, J. W. \& Costello, A. B. (2009). Best practices in exploratory factor analysis: Four recommendations for getting the most from your analysis. Pan-Pacific Management Review, 12(2), 131-146.

Ostrowski, P. L., O’Brien, T. V., \&Gordon, G. L. (1993). Service quality andcustomer loyalty in the commercial airline industry.Journal of Travel Research, 32(2), 16-24.

Oxford, R., \& Burry-Stock, J. (1995). Assessing the use of language learning strategies worldwide with the ESL/EFL version of SILL.System,23, 1-23.

Oyewole, P., Sankaran, M., \&Choudhury, P. (2008). Information communication technology and the marketing of airline services in Malaysia: A Survey of market participants in the airline industry.Services Marketing Quarterly, 29(4), 85-103.

Pagell, M., \& Krause, D. (2002). Strategic consensus in the supply chain: Exploring the manufacturing purchasing link.International Journal of Production Research, 40(13), 3075-3092.

Parasuraman, A., Zeithaml, V. A., \&Berry, L. L. (1985). A conceptual model of service quality and its implications for future research.Journal of Marketing, 49, 41-50. 
Parasuraman, A., Zeithaml, V.A., \&Berry, L. L. (1988). SERVQUAL: A multi-item scale formeasuring consumer perceptions of the service quality.Journal of Retailing, 64(1), 12-40.

Park, J.W., Robertson, R., \& Wu, C-L. (2006). The effect of airline service quality on passengers' behavioural intentions: A Korean case study. Journal of Air Transport Management, 10(6), 435-439.

Peng, M. W. (2009). Global business.South-Western Cengage Learning.

Petkova, B., \& Dam, L. (2014). The impact of environmental supply chain sustainability programs on shareholder wealth.International Journal of Operations \& Production Management, 23-38.

Podsakoff, P. M., MacKenzie, S. B., Lee, J. Y., \& Podsakoff, N. P. (2003). Common method biases in behavioral research: A critical review of the literature and recommended remedies. Journal of Applied Psychology, 88 (5), 879-903.

Polit, D.F., \& Beck, C. T.(2009).International differences in nursing research. Journal of Nursing Scholarship, 41, 44-53.

Prajogo, D., Chowdhury, M., Yeung, A. C. L. \& Cheng, T. C. E.(2012).The relationship between supplier management and firm's operational performance: A multi-dimensional perspective. International Journal of Production Economics, 136(1), $123-130$.

Prajogo, D., Tang, A., \& Lai, K.-H. (2014). The diffusion of environmental management system and its effect on environmental management practices.International Journal of Operations \& Production Management, 12-27.

Rosen \& Karwan (1994). Prioritizing the dimensions of service quality.International Journal of Service Industry Management, 5(4), 39-53.

Rosenzweig, C., Tubiello, F., Goldberg, R., Mills, E., \& Bloomfield, J. (2002). Increased crop damage in the U.S. from excess precipitation under climate change.Global Environment Change, 12, 197-202.

Saha, G.C.,\&Theingi (2009).Service quality, satisfaction, and behavioural intentions: A study of low-cost airline carriers in Thailand.Managing service quality.An International Journal, 19(3), 350-372.

Saleh, R.A., Sweis, R.J.,\& Mahmoud, S. F. I. (2018).Investigating the impact of hard total quality management practices on operational performance in manufacturing organizations: Evidence from Jordan.Benchmarking: An International Journal, 25(7), $2040-2064$.

Salem, H. 2013. Organisationalperformance management and measurement. The Lebanese Experience,1-15.

Sarstedt, M., \&Mooi, E.(2014).A concise guide to market research.The process, data, and methods using IBM SPSS statistics.Springer.

Schroeder, R. G., Shah, R., \& Xiaosong-Peng, D. (2011). The cumulative capability “sand cone"model revisited: a new perspective for manufacturing strategy. International Journal of Production Research, 49(16), 4879-4901.

Schwab, D.P. (1980). Construct validity in organizational behavior. In Staw, B. M. and Cummings, L. L. (Eds.). Research in organizational behavior.343. JAI Press.

Seristö, H., \&Vepsäläinen, A. P. J. (1997). Airline cost drivers: Cost implications of fleet, routes, and personnel policies. Journal of Air Transport Management, 3(1), 11-22.

Sharma, S., \&Modgil, S. (2020). TQM, SCM and operational performance: an empirical study of Indian pharmaceutical industry. Business Process Management Journal,26(1), 331-370 DOI 10.1108/BPMJ-01-2018-0005

Singer, E., Groves, R. M., \& Corning, A. D. (1999). Differential incentives: Beliefs about practices, perceptions of equity, and effects on survey participation. Public Opinion Quarterly, 63(2), 251-260. https://doi.org/10.1086/297714

Slack, N., Chambers, R.,\& Johnston, R. (2007).Operations management.Sixth edition.Prentice Hall.

Śledzik, K. (2013). Knowledge Based Economy in a Neo-Schumpeterian point of view Equilibrium. Quarterly Journal of Economics and Economic Policy, 8(4), 67-77.

Spector, P. E. (1992). Summated rating scale construction. Sage.

Sultan, F.,\& Simpson, M. C. (2000). International service variants: airlinepassenger expectations and perceptions of service quality. Journal of Service Management,14(3), 188-216.

Taylor, S. A.,\& Hunter, G. L. (2003).The impact of loyalty with e-CRM software and e-services. International Journal of Service Industry Management,13(5), 452-74.

Tenenhaus, M., Vinzi, V. E., Chatelin, Y. -M., \&Lauro, C. (2005). PLS path modelling.Computational Statistics and Data Analysis,48(1), $159-205$.

Tiernan, S., Rhoades, D. L., \& Waguespack Jr, B.(2008).Airline service quality: Exploratory analysis of consumer perceptions and operational performance in the USA and EU. Journal of Service Theory and Practice, 18(3), 212-224.

Truitt, L.J., \& Haynes, R. (1994). Evaluating service quality and productivity in the regional airline industry. Transport Journal, $33(4), 21-32$. 
Tsikriktsis, N. (2007). The effect of operation performance and focus on profitability: A longitudinal study of the U.S. airline industry. Manufacturing \& Service Operations Management, 9(4), 506-517.

Tzanakakis, K. (2013). The effect of track stiffness on track performance. In: The railway track and its long term behaviour.79-87. Springer.

Vanichchinchai, A., \&lgel, B.(2011).The impact of total quality management on supply chain management and firm's supply performance.International Journal of Production Research, 49(11), 3405-3424.

Vaske, J. J. (2008). Survey research and analysis: Applications in parks, recreation and human dimensions. Venture.

Vaske, J. J., Beaman, J., \&Sponarski, C. (2016). Rethinking internal consistency in Cronbach's Alpha.Leisure Science, 0(0), 1-11.

Vlachos, I., \& Lin, Z. (2014). Drivers of airline loyalty: Evidence from the business travelers in China. Transportation Research Part E Logistics and Transportation Review, 71, 1-17.

Wang, C. L., \& Ahmed, P. K. (2004). The development and validation of the organizational innovativeness construct using confirmatory factor analysis. European Journal of Innovation Management, 7(4), 303-313.

Wang, M.,\& Stanley, J. (1970). Differential weighting: A review of methods and empirical studies. Review of Educational Research, 40, 663-705.

Ward, P. T., Duray, R., Leong, G. K., Sum,C-C. (1995). Business environment,operations strategy, and performance: An empirical study of Singapore manufacturers. Journal of Operations Management, 13, 99-115.

Wells, A. T., \& Wensveen, J. G. (2004).Air transportation: A management perspective. (5th ed.). Thomson-Brooks.

Whiteley, R. C. (1991). The customer-driven company: Moving from talk to action. Addison-Wesley.

Wyman, O. (2012). Guide to airport performance measures. Airports Council International. Montreal: Oliver Wyman Inc.

Yong, A. G.,\& Pearce, P. (2013).A beginner's guide to factor analysis: Focusing on exploratory factor analysis. Tutorials in Quantitative Methods for Psychology, 9(2), 79-94.

Yu, S., Alper, H., Nguyen, A-M., Brackbill, R., Turner, L.,Walker, D., Maslow, C., \& Zweig, K. (2017). The effectiveness of a monetary incentive offer on survey response rates and response completeness in a longitudinal study.BMC Medical Reserach Methodology, 17, 77 (2017).https://doi.org/10.1186/s12874-017-0353-1

Zhang, G. P., \& Xia, Y. (2013). Does Quality Still Pay? A re-examination of the relationship between effective quality management and firm performance.Production of Operations Management, 22, 120-136.

Zohar, D. (1980). Safety climate in industrial organizations: Theoretical and applied implications. Journal of Applied Psychology, 65(1), 96-102. 